\title{
Current State of Commercial Banks in a Digital Economy
}

\author{
Kanishcheva N.A. \\ Yaroslav-the-Wise Novgorod State University, \\ Veliky Novgorod, Russia, \\ Natalya.Kanischeva@novsu.ru
}

\begin{abstract}
The digital economy is more and more confidently entering the ordinary life of citizens and does not seem so fantastic as it did several years ago. Smart city, digital economic platform, digital medicine, robotics and much more have long entered the everyday life of any person. The introduction and development of the digital economy is inevitable and necessary for any country. The active introduction of the digital economy in Russia has been carried out since 2018 in accordance with the decree of the President of the Russian Federation Vladimir Putin dated May 7, 2018 No. 204 "On national goals and strategic objectives of the development of the Russian Federation for the period until 2024", The process of "digitalization" began in the $1970 \mathrm{~s}$ by replacing analog systems with digital ones. Digitalization has penetrated quite deeply into all spheres of society. Infrastructure based on electronic interaction is becoming the newest vector for the formation and development of the global economy, which is acquiring digital status. The rapid development of digital technologies in recent years leads to a paradigm shift in economic relations, moving from a real component to a virtual space. Nowadays, the ubiquitous appearance of electronic devices and gadgets has facilitated the implementation of many different functions and operations. Modern science opens new horizons every day, and the world is increasingly striving for digitalization. New technologies are necessary to make a profit with minimal costs, as well as to ensure complete security, confidentiality, and identification of important information for business entities of various fields of activity.
\end{abstract}

Keywords-banking system, information environment, digital technologies, digitalization of the economy

\section{INTRODUCTION}

The digital revolution is making significant changes in our life and in society as a whole, unprecedented and rapidly changing everything in its path on an unprecedented scale, in the process of which not only many new opportunities are formed, but also a number of colossal problems arise. The latest devices and technologies make a significant contribution to achieving goals and solving various problems in the field of stable functioning and development of the country, but it should be noted that a positive outcome is not guaranteed for the results of such actions. The newest models of business processes that have appeared, as well as network systems based on collective methods of production and consumption, transform the existing economic relations and give rise to the need to develop new, innovative solutions for managing a modern bank. The further creation and use of digital technologies plays a major role in the development of both an individual commercial bank and the country's economy as a whole [1].

\section{RESULTS AND DISCUSSION}

It is important to introduce new technologies, digitalize the bank, constantly change and meet customer needs to implement the main components of a commercial bank. In connection with the Covid-19 pandemic, the problem of digitalization of various spheres of public life, including the economy, has become the most urgent. If you look at the work of commercial banks in Russia, you will notice that most banks in the Russian Federation support remote work, work online, and business processes can be digitized. That is why we can say that Russia has become one of the world leaders in the development of cashless payments.

The development of digitalization in the banking sector is one of the most important tasks for the development of the Russian economy. So banks became the first and, at the moment, the most developed organizations in the digital economy in Russia. According to KPMG, as of January 1, 2020, about $86 \%$ of Russian banks have already begun the process of implementing a digital transformation program, however, the level of digitalization of the national market is about $63 \%$, which is $23 \%$ lower than banking digitalization. The banking sector became the initial target for the introduction of the digital economy due to a number of the following reasons:

- full use of digital products is the main condition in the activities of banks striving to be competitive in all segments;

- the use of digital technologies allows banks to improve the quality of identifying the needs and desires of customers with further formation of individual proposals based on the identified needs; thus, the quality of interaction between banks and customers is improving;

- digital technologies enable banks to interact with customers, regardless of the location of the financial 
institution; interact at a distance;

- new technologies make transactions more open, faster and more understandable;

- digital technologies allow reducing the cost of services and products of the bank by reducing costs $[2,3]$.

Building platforms for banks increases their attractiveness to customers and stakeholders of interconnected businesses, thereby providing opportunities for building a banking ecosystem. Social factors and the development of new digital information technologies have a positive impact on investment in banks [4]. The main tools for digitalizing the activities of commercial banks include:

- big data in proactive communication with clients;

- marketplace;

- robotization;

- blockchain technology;

- use of chat bots and virtual assistants;

- use of biometrics in the banking sector.

Today, it is very important for banks to introduce flexible working methods to meet the constantly changing and growing expectations of customers, resulting in the so-called "electronic banking", which is a multifunctional system for informing the client and remote management of his accounts. Electronic banking services include:

- account statements for the client;

- information about banking products (deposits, loans, securities);

- applications for opening deposits and obtaining loans and bank cards;

- internal transfers to bank accounts;

- transfers to accounts in other banks;

- currency conversion.

If the first two types of services can be carried out using only mobile communication, then the rest, as a rule, require an Internet connection.

According to the results of research conducted by the AllRussian Center for the Study of Public Opinion in 2019, banking operations became the most popular online service. Thus, about $61 \%$ of respondents most often make banking transactions using an online bank. By the end of 2019, the most common digital tools used by banks under the Digital Economy of the Russian Federation program were artificial intelligence, technologies for analyzing large amounts of data, robots, chat bots and recognition technologies.

Artificial intelligence technology is aimed at solving many problems, the primary of which is the optimization of digital banking instruments and products for the needs of customers. The introduction of artificial intelligence makes it possible to simplify the process of collecting and analyzing data, using speech and video recognition technology, as well as neural networks and biometric identification [5].
An example of the use of artificial intelligence is the Sberbank online bank application, which analyzes the behavior and actions of the client using algorithms. This analysis allows the application to recommend to the client those operations that are most necessary for them and which they performed earlier.

Artificial intelligence is also actively used to determine credit scoring, which allows banks to see the client's solvency and calculate a certain limit for issuing loans and other similar products.

The use of this kind of digital tools allows banks to increase the level of protection against fraud. The introduction of biometric analysis allowed banks to identify customers and identify fraud. The biometrics system uses not only fingerprints, but also a number of exceptional characteristics to determine the client's face. This technology is called a biometric face descriptor. Also, this system allows recognizing the client's voice by seventy parameters.

However, in practice, this technology also carries the threat of fraud with it by recording the client's voice with supporting phrases. To solve this problem, banks began to correlate voice recognition with facial expressions.

The biometrics system allowed bank customers to access services requiring mandatory identification, remotely, as well as to use the services of banks regardless of the region and even the country of their location.

The primary and basic tool is "Big Data", which is based on the analysis of large amounts of data. Big Data allows analyzing a significant amount of information in any form and from various sources. This technology allows storing, processing and displaying reliable information about the "digital footprint" of any client, which gives banks the opportunity to develop individual proposals, allocate resources optimally and develop a digitalization strategy.

Analysis using the Big Data tool allows classifying bank customers into segments according to certain profiles, compiled with this tool based on the client's expenses system and identification of transaction directions. This technology allows revealing the structure of expenses and see the client's credit history for risk assessment.

When working with clients and counterparties and when archiving documents, most banks began to use digital workflow using optical character recognition (OCR). OCR technology is used to work with large amounts of text and formats any image in an editing format. OCR verifies that documents are filled in correctly when scanned. If filled in correctly, scanned images are automatically sent to a bank employee for verification, after which scanned documents are stored in digital archives for further use. This technology allows reducing document flow and time, and also eliminates the loss of documents [6].

This technology is actively used in Rosselkhozbank, which allowed the bank's employees to increase the number of processed pages per month to four million, significantly reduce the level of risks of damage to documents and accelerate the interaction of the head office with branches.

Chat bots (voice assistants, electronic assistants) are used to increase the speed and quality of work between the bank and the client, which practically leads to minimization of waiting for a response from a bank employee. Chatbots operate around 
the clock, which allows customers to get the information they need at any time. Many banks began to use chat bots in social networks and applications (VKontakte, Viber, WhatsApp) for younger clients.

In recent years, there has been a trend towards mobile banking. For many clients, this method has become the most popular for carrying out any operations and obtaining information. The share of customers using mobile banks is constantly growing, which confirms the effective use of mobile banks, gives a competitive advantage over banks that do not pay attention to the development of online banks. The most common operations carried out using mobile applications at the end of 2019 are money transfers (57\%), payments for utilities, Internet services and others (54\%), while about $37 \%$ make payments using QR codes or barcode codes.

The digitalization of the banking sector is slowing down for several reasons. Unavailability and ignorance of bank customers is the primary reason. According to research conducted by the NAFI Analytical Center, clients are not aware of the possibility of using chat bots $(58 \%)$, voice assistants $(48 \%)$, correspondence with other clients $(51 \%)$, etc. They also identified services that customers rarely use: submitting applications for the registration of any products through online banks (39\% use this service), financial news and advice (30\%), and getting a "cashback" (35\%).

The most global problem of bank digitalization is information security risk. Online banks are the most vulnerable in terms of payment security and personal data storage. The development of digital products has led to the development of Internet fraud, and the use of artificial intelligence for fraudulent purposes is a risk of failure and loss of not only banking data, but also confidential information in all areas of human activity.

Another major problem is the lack of legal regulation of blockchain and digital product distribution systems that dominate the modern economy. In the context of digitalization, tasks appear in the direction of banks along the path of developing a symbiosis of banking and fintech. This direction will allow assessing the industry's capabilities to introduce new organizational forms, and classifying participants by the level of adoption of new technologies.

Some aspects of digitalization of banking pose certain threats to both commercial banks and their clients, primarily due to cyber attacks, high operational risks, rising unemployment in the banking sector, and also due to the fact that some of the clients are unable to exist in the digital space. To minimize these threats, it is necessary to do the folowing:

- modernize the banking business environment, taking into account the trends in the development of the digital economy (regulatory, professional, cognitive issues);

- check the reliability of bank clients in terms of transaction thresholds;

- launch programs to improve the financial literacy of the population.

At the present stage, the issues of the impact of digitalization on the effective functioning of the banking system and the interaction of fintech companies with banks are becoming important. Ensuring complete cybersecurity in mobile banking creates preconditions for online fraud, which in the future may lead to insufficient reliability of smartphones. The goal of developing banking cybersecurity is to create a mechanism to protect information in the banking sector, but today most small commercial banks do not have sufficient resources to ensure cybersecurity. The main concern in the area of cyber risk for banking institutions is certain regulatory and supervisory requirements to manage such risks. There is a need to amend regulatory documents in order to develop the banking sector and manage risks efficiently.

It can be said that banks around the world have more cybercrime risks than other companies, which is why financial institutions should pay attention to cybersecurity. Smaller banks remain the most vulnerable because they are unable to allocate large budgets for cybersecurity. The digitalization of banking processes in order to create new economic relations and stimulate market development is important, however, in the context of digitalization, the threat of cyber attacks creates problems for customers and can lead to undermining the reputation of the bank. In the context of globalization, financial institutions need to attract additional investment to manage cyber risks and build relationships with stakeholders to share information and cover the risks associated with cyber attacks, and thereby contribute to sustainable financial growth. In the future, banks need to modernize platforms and their operations in the context of digitalization in order to strengthen management practices, reduce operational risk, improve organizational structure and management of operational risk insurance $[1,7]$.

The main reasons for the emergence of cyber threats to a bank can be divided into several groups:

- lack of constant updating of legislation and uniform safety standards;

- lack of funding from the banks themselves;

- lack of corporate culture in the field of cybersecurity within the bank.

All this requires the inclusion of the following elements in the bank's operating activities:

- training of cybersecurity personnel in the format "anytime, anywhere"; educational materials should be presented in a simplified form for perception: using videos, animations and other convenient tools; it can also be effective to send periodic reminders of information security requirements with information on the latest events and news, which will help employees to keep abreast of the latest trends and perceive cyber security as a daily task;

- developing a plan in case of an attack; such a plan describes the actions of various team members in various incident scenarios, from attacking a website to stealing money from customer accounts; discussing the action plan with professional moderation will help identify key issues that need to be addressed before the banking system is hacked; also the creation of operational security centers that monitor threats and respond to them in a timely manner is relevant;

- regular cybersecurity audits (an important aspect is the qualifications of the auditor: they must have sufficient 
competence to identify problem areas in banking security);

- training clients on basic security rules (this will help reduce additional risks of unauthorized access to information using one-time passwords and two-factor authentication) $[8,9]$.

Diversification of banking risks is one of the main methods of sustainable development of commercial banks in the global economy and, with sustainable financing, has a positive effect on the capitalization of banks, since can it enable banks to increase cash flows and generate additional income. Therefore, managing risk diversification requires a new strategy in the context of digitalization. World experience in bank diversification shows that it is necessary to apply a set of strategies and methods of risk management to achieve sustainable development of the financial system. Studying bank customers and their needs in modern society requires constant international communication and the development of partnerships in order to create the conditions necessary for the provision of safe financial services and sustainable growth of banks. An effective approach to monitoring and assessing risks should seek to identify potential threats such as:

- loss of data integrity and unauthorized access to customer data;

- violation of the technical system in the information space;

- defects and failures in the operation of the technical system;

- cyberattacks [10].

\section{CONCLUSION}

In the near future, the main directions of digitalization of the banking sector will be the organization of the effective use of digital products, taking into account the needs of customers.

Digitalization is the main product for the development of not only the banking sector, but the entire economy, thanks to the convenience and quality of the use of innovative technologies. The current state of the Russian banking sector has all the prerequisites for its future digital development and world leadership in this area [11].

Banks must accelerate the digitalization process across their entire business to remain competitive in the customer age. Customers want accounts to open in minutes and expect banks to have access to all of their data. Availability 24/7, intuitive interfaces, real-time execution and personalized attitude with global consistency and zero errors become differentiating factors, while basic products and services become commercialized [12].

In addition to automating existing processes, banks must reduce the complexity and response time of all customer interactions, and develop automated decision making with better regulatory compliance. Data management and analytics platforms are critical to achieving this goal. They provide insight into customer needs, faster and more efficient decision making, and effective performance tracking. Within the company, new professional units may be required, such as data scientists and user experience designers. However, banks should focus on their core strengths and, at the same time, where appropriate, seek internal and external strategic partnerships to enhance their capabilities $[13,14]$.

However, no transformation process can be fully planned in advance. It is also difficult to predict the most successful approaches. Some can form effective crossfunctional teams; others - to create laboratories for innovation and digitization; still others are to sponsor initiatives within their organizations. Participation at scale, harnessing collective wisdom both internally and through partners, facilitating collaborative, mobile and responsive processes will all be essential to drive business growth.

It can be concluded that as more aspects of banking are digitalized, banks will pay more attention to several key development areas, including open banking and fintech. Going forward, banks can be expected to invest heavily in building industry expertise, leveraging data and analytics to improve customer experience, and move to cloud-based deployments to stay relevant in an increasingly competitive environment. It is also possible that the process of introducing digital technologies into the economy can go even faster, so banks should be as well prepared as possible for the possibility of "accelerated digitalization".

\section{References}

[1] M. Ertz, and É. Boily, "The rise of the digital economy: Thoughts on blockchain technology and cryptocurrencies for the collaborative economy", International Journal of Innovation Studies, 2019, vol. 3(4), pp. 84-93. DOI: 10.1016/j.ijis.2019.12.002

[2] A. Wright, and P. De Filippi, "Decentralized blockchain technology and the rise of lex cryptographia", Social Science Research Network Electronic Journal, 2015. DOI: 10.2139/ssrn.2580664

[3] C.I. Mbama, and P.O. Ezepue, "Digital banking, customer experience and bank financial performance: UK customers' perceptions", International Journal of Bank Marketing, 2018, vol. 36(4), pp. 230-255. DOI: 10.1108/JJBM-11- 2016-0181

[4] K.J. Trainor, J.M. Andzulis, A. Rapp, and R. Agnihotri, "Social media technology usage and customer relationship performance: a capabilitiesbased examina tion of social CRM", Journal of Business Research, 2014, vol. 67(6), pp. 1201-1208. DOI: 10.1016/j.jbusres.2013.05.002

[5] E.A. Borkova, K.A. Osipova, E.V. Svetlovidova, and E.V. Frolova, "Digitalization of economy on the example of banking system", Kreativnaya ekonomika, 2019, vol. 13(6), 1153-1162. (In Russ.). DOI: 10.18334/ce.13.6.40734

[6] F. Khanboubi, A. Boulmakoula, and M. Tabaa, "Impact of digital trends using IoT on banking processes", in Proceedings of $10^{\text {th }}$ Internatinal Conference on ANT, 2019, pp. 77-84. DOI: 10.1016/j.procs.2019.04.014

[7] A.B. Youssef, S. Boubaker, B. Dedaj, and M. Carabregu-Vokshi, "Digitalization of the economy and entrepreneurship intention", Technological Forecasting and Social Change, 2020. DOI: $10.1016 /$ j.techfore. 2020.120043

[8] A.V. Thakor, "Fintech and banking: What do we know?", Journal of Financial Intermediation, 2019, vol. 41, pp. 3-13. DOI: 10.1016/j.jfi.2019.100833

[9] R.E. Krainer, "Economic stability under alternative banking systems: Theory and policy", Journal of Financial Stability, 2017, vol. 31, pp. 107 118. DOI: $10.1016 /$ j.jfs.2017.05.005

[10] S. Jatic, M. Ilic, L. Miletic, and A. Markovic, "Strategy of Swiss Banking Sector towards Digitalization Trends", International Journal of Economic and Law, 2017, vol. 7, pp. 61-72.

[11] K.S. Warner, and M. Wager, "Building dynamic capabilities for digital transformation: An ongoing process of strategic renewal", Long Range Planning, 2019, vol. 52(3), pp. 326-349. DOI: 10.1016/j.lrp.2018.12.001

[12] F. Allen, A. Demirguc-Kunt, L. Klapper, and M.S.M. Peria, "The foundations of financial inclusion: Understanding ownership and use of formal accounts", Journal of Financial Intermediation, 2012, vol. 27, pp. 1-30.

[13] T. Beck, A. Demirgüc-Kunt, and R. Levine, "Finance, inequality and the poor", Journal of Economic Growth, 2007, vol. 12(1), pp. 27-49.

[14] P. Gomber, J.A. Koch, and M. Siering, "Digital finance and FinTech: Current research and future research directions", Journal of Business Economics, 2017, vol. 87(5), pp. 537-580. 